\title{
O CURSO DE LICENCIATURA EM PEDAGOGIA: UMA ANÁLISE DAS ADEQUAÇÕES NORMATIVAS E CURRICULARES
}

\begin{tabular}{c} 
THE PEDAGOGY COURSE: \\
ANALYSIS OF NORMATIVE AND CURRICULAR ADAPTATIONS \\
El GRADO EM PEDAGOGÍA: \\
ANÁLISES DE LOS AJUSTES NORMATIVOS Y CURRICULARES \\
\hline
\end{tabular}

Debora Cristina Jeffrey ${ }^{1}$ Ana Elisa Spaolonzi Queiroz Assis ${ }^{2}$ Luciane Grandin ${ }^{3}$

\section{RESUMO}

O Curso de Licenciatura em Pedagogia, entre os anos de 2002 e 2015, tem sido influenciado por normativas nacionais que induzem a constituição de um modelo de formação profissional, sem que se estabeleça uma relação à política de formação de professores no Brasil. Neste sentido, o artigo problematiza o processo de adequação normativa e curricular envolvendo o Curso em questão, destacando as principais concepções de formação de professores no país e sua influência em determinações legais e curriculares, a trajetória da legislação na última década, produzida pelo Conselho Nacional de Educação e os núcleos de formação enfatizados. A fim de auxiliar a análise, é retratado o caso de um Curso de Licenciatura em Pedagogia de uma Universidade Estadual de São Paulo e sua dinâmica interna para atender às adequações normativas e curriculares estabelecidas nos últimos anos. Evidencia-se que, houve um número significativo de orientações normativas em âmbito nacional referente aos Cursos de Licenciatura no país. Essas orientações, por sua vez, influenciam diretamente a constituição dos projetos pedagógicos dos Cursos de Licenciatura, sem que a formulação de uma agenda e a constituição de uma política de formação de professores fossem efetivamente implementados.

PALAVRAS-CHAVE:. Pedagogia. Licenciatura. Formação de professores. Política educacional.

\begin{abstract}
The Pedagogy Course, between 2002 and 2015, has been influenced by national regulations that induce the formation model without any establish relation to teacher education policy in Brazil. The article discusses the process of normative and curricular adaptation involving the course in question, highlighting the main teacher training concepts in the country and its influence on legal and curricular determinations, the legislation's trajectory legislation on the last decade, produced by the National Education Council. In order to assist the analysis, it is reported the case of a Pedagogy Course of the State University of São Paulo and its internal dynamics to meet the regulatory and curricular adjustments established in recent years. It is evident that there were a significant number of normative guidelines nationwide related to undergraduate programs in the country. These guidelines, in turn, directly influence the formation of the pedagogical projects of undergraduate programs without formulating an agenda and the establishment of a teacher training policy that it can be effectively implemented.
\end{abstract}

\footnotetext{
${ }^{1}$ Mestre em Educação pela UNICAMP e doutorado em Educação pela USP; professora livre-docente na área de Política Educacional pela UNICAMP. E-mail: debora.jeffrey@gmail.com

${ }^{2}$ Graduação em Pedagogia e mestrado em Educação pela PUC-Campinas; doutorado em Educação pela

UNICAMP. Professora da Faculdade de Educação-UNICAMP. E-mail: anaelisasqa@ @mail.com

${ }^{3}$ Graduação em Pedagogia e mestre em Educação pela UNICAMP. Pedagoga da Coordenação de Graduação da

FE / UNICAMP. E-mail: coordped@unicamp.br

Submetido em: 25/08/2016 - Aceito em: 10/09/2016.

\begin{tabular}{|c|c|c|c|c|c|c}
\hline (c) Rev. Inter. Educ. Sup. & Campinas, SP & v.2 & n.2 & p.291-310 & maio/ago. 2016 & ISSN 2446-9424
\end{tabular}
}


KEYWORDS: Pedagogy. Undergraduate. Teacher training. Educational policy.

\section{RESUMEN}

La Licenciatura en Educación, entre los años 2002 y 2015, ha sido influenciada por las normas nacionales que inducen la formación de un modelo de formación profesional, que no establezca una relación directa a una política de formación docente en Brasil. En este sentido, el artículo discute el proceso de adaptación normativa y curricular que del curso y su relación con los principales conceptos de formación docente en el país y su influencia en las determinaciones legales y curriculares, la trayectoria de la legislación en la última década, producida por el Consejo Nacional del Educación y los Centros de Formación. Con el fin de ayudar al análisis, retrata el caso de una Licenciatura en Educación de la Universidad del Estado de San Pablo y su dinámica interna para cumplir con los ajustes normativos y curriculares establecidos en los últimos años. Es evidente que hubo un número significativo de directrices normativas a nivel nacional relacionadas con la Licenciatura en Educación del país. Estas directrices, a su vez, influyen directamente en la formación de los proyectos pedagógicos de los grados sin formular una agenda y establecer una política de formación docente que se puede implementar efectivamente.

PALABRAS CLAVE: Pedagogía. Grado. Formación del profesorado. Política educativa.

\section{INTRODUÇÃO}

O curso de Licenciatura em Pedagogia, nas últimas décadas, tem ampliado as possibilidades de perfil do egresso, de modo a atender às orientações normativas, em particular do Conselho Nacional de Educação (CNE), e demandas educacionais, com impacto direto nas propostas curriculares das Instituições de Ensino Superior (IES).

Conforme apontou Saviani (2009), há predominância de dois modelos de formação docente no Brasil: 1) com ênfase em conteúdos culturais-cognitivos - centrado na cultura geral e no domínio específico dos conteúdos da área de conhecimento correspondente à disciplina em que o estudante irá lecionar; 2) com ênfase na formação pedagógico-didático para a efetiva preparação do estudante à prática pedagógica e didática.

A efetividade destes dois modelos de formação docente, na análise de Saviani (2009), expressam as sucessivas mudanças que ocorreram neste processo, apresentando um quadro de descontinuidade, mas sem rupturas nestas ênfases, em decorrência da precariedade de políticas formativas e ausência de um padrão consistente para a formação de profissionais habilitados para atenderem às demandas educacionais existentes. Tal problemática, de acordo com Libâneo (2002) também reflete as implicações da pós-modernidade para os processos de formação docente, que recentemente vem se caracterizando pelos modismos pedagógicos, frágil repertório teórico, instabilidade teórica e, muitas vezes na baixa capacidade crítica do professorado.

Diante deste fato, para Fiorentini e Crecci (2013), as proposições envolvendo a formação inicial de professores no Brasil, fundamentam-se ora em uma perspectiva de formação profissional (ação formativa externa visando a transformação do sujeito) e em outros momentos pela perspectiva de desenvolvimento profissional docente (ação formativa permanente para a atuação profissional em um campo específico). 
Enquanto a perspectiva de formação profissional centra-se na ênfase dos conteúdos culturais-cognitivos necessários à atuação docente, a perspectiva do desenvolvimento profissional docente além de destacar a formação didático-pedagógico do egresso, apresenta uma definição abrangente, que segundo André (2010), envolve os processos de preparação, profissionalização e socialização dos professores, com o objetivo de proporcionar a aprendizagem do aluno.

Além disso, de acordo com André (2010), a perspectiva do desenvolvimento profissional docente pauta-se na valorização da concepção do profissional, sua representação social e identidade do profissional, fato que expressa a ideia de continuidade, evolução e rompimento com a formação inicial e continuada, ao compreender que esse será um processo permanente e de individualização do processo formativo.

Neste sentido, André (2010, p. 177), ainda ressalta que essa perspectiva ao enfatizar as representações, saberes e práticas do professor, não tem favorecido a articulação com os contextos em que tem sido produzidos, mudando o foco dos cursos de formação para a formação do professor isoladamente, reforçando “[...] uma visão da mídia, com amplo apoio popular de que o professor é o principal (talvez o único) responsável pelo sucesso/fracasso da educação".

Porém, além da crença que a subjetivação da formação de professor representaria um avanço, Gatti (2014a; 2014b), ao analisar a formação inicial de professores para atuação na educação básica, identificou algumas problemáticas que precisam ser levadas em consideração, de modo a superar essa perspectiva fragmentada, com destaque para: a) a ausência de uma política nacional específica para as licenciaturas; b) a existência de Diretrizes Curriculares de Curso de formação de professores isoladas; c) a constituição de currículos fragmentados nos Cursos; d) despreparo dos docentes das IES para formar professores; e) evasão considerável nos Cursos; f) estágios supervisionados sem projeto ou acompanhamento.

Diante deste diagnóstico, Gatti et al (2011, p. 267) consideraram que além destes fatores, há uma outra problemática que tem influenciado as propostas e modelos curriculares dos Cursos de formação de professores, ao alertarem o fato de que:

Uma tônica predominante é que as ações de todos os entes federados se têm mostrado crescentemente pautadas pelos resultados das avaliações padronizadas dos alunos da educação básica. Isso é um é indicativo de que as redes de ensino estão mais mobilizadas e as políticas, em princípio, mais focalizadas nos alunos e no seu direito de aprender. Significa também que as formas de funcionar dos sistemas escolares e as formas de condução, controle e avaliação da atuação docente estão passando por profundas alterações, em vista do modelo de resultados (GATTI et al. 2011, p. 267). 
Considerando o diagnóstico realizado por Gatti (2014) e colaboradores (2011), é possível compreender que o Curso de Pedagogia, que de acordo com os dados do Censo do Ensino Superior (2013) apresenta a maior representatividade entre os Cursos de Licenciatura (1.353.614 matrículas), contabilizando 611.111 matrículas $(45,14 \%)$, tem realizado adequações normativas e pedagógicas para atender às demandas educacionais da educação básica, bem como dos sistemas de ensino.

Assim, de modo a favorecer a trajetória normativa e pedagógica do Curso de Pedagogia entre os anos de 2002 a 2015, o presente artigo se estrutura.

\section{AS ADEQUAÇÕES NORMATIVAS NO CURSO DE LICENCIATURA EM PEDAGOGIA (2001-2015)}

De acordo com Dourado (2015, p. 300) a última década caracteriza-se pelos movimentos realizados, a fim de repensar a formação de professores, em especial no que tange às Resoluções do CNE que tendem a dar "maior organicidade para a formação de profissionais do magistério da educação básica, incluindo a rediscussão das Diretrizes e outros instrumentos normativos acerca da formação inicial e continuada”.

Neste contexto, podemos destacar três Resoluções principais, a saber: Resolução CNE/CP n. ${ }^{\circ} 1$ de 2002, Resolução CNE/CP n. ${ }^{\circ} 1$ de 2006 e Resolução CNE/CEB n. ${ }^{\circ} 2$ de 2015.

A variedade de temas que cada Resolução trata nos permitiria discutir inúmeros assuntos referentes à formação. Assis (2007), por exemplo, problematizou o lócus de formação do professor dos anos iniciais diante da quantidade de possibilidades, inclusive irregulares como os cursos normais, para que esta formação ocorresse, assunto pendente ainda nos dias atuais; todavia neste artigo daremos ênfase à prática enquanto componente curricular e o tratamento que recebeu frente a estes atos normativos da esfera Federal.

QUADRO 1. Prática enquanto componente curricular nas Resoluções do CNE

\begin{tabular}{|l|l|l|}
\hline Atos Normativos Federais & Ano & \multicolumn{1}{|c|}{ Assunto } \\
\hline Resolução CNE/CP n.1/2002 & 2002 & $\begin{array}{l}\text { Institui Diretrizes Curriculares Nacionais para a } \\
\text { Formação de Professores da Educação Básica, em } \\
\text { nível superior, curso de licenciatura, de graduação } \\
\text { plena. }\end{array}$ \\
\hline Resolução CNE/CP n. 1/2006 & 2006 & $\begin{array}{l}\text { Institui Diretrizes Curriculares Nacionais para o } \\
\text { Curso de Graduação em Pedagogia, licenciatura. }\end{array}$ \\
\hline Resolução CNE/CEB n.2/2015 & 2015 & $\begin{array}{l}\text { Define as Diretrizes Curriculares Nacionais para a } \\
\text { formação inicial em nível superior (cursos de } \\
\text { licenciatura, cursos de formação pedagógica para } \\
\text { graduados e cursos de segunda licenciatura) e para a } \\
\text { formação continuada. }\end{array}$ \\
\hline
\end{tabular}

Fonte: Atos normativos ferederais. 
De acordo com o quadro, na Resolução CNE/CP n. ${ }^{\circ} 1$ de 2002 os artigos 12 e 13 direcionam a discussão da prática enquanto componente curricular. Das três Resoluções, esta é a única em que não se define a carga horária para as atividades práticas, vez que se dirige ao conjunto de cursos de formação de professores, indicando que cada curso terá sua duração definida pelo Conselho Pleno em Parecer ou Resolução específica (art. 12, caput Resolução CNE/CP n. ${ }^{\circ} 1$ de 2002).

No que tange ao tempo, a única menção que faz é no artigo $13, \S 3^{\circ}$ (Resolução $\mathrm{CNE} / \mathrm{CP}$ n. ${ }^{\circ} 1$ de 2002) para que seja desenvolvido, a partir da segunda metade do curso, sendo avaliado conjuntamente pela instituição formadora e a instituição lócus de estágio. Esta situação foi regulamentada em 2008, pela Lei n. ${ }^{\circ} 11.788$ que trata das relações de estágio dos estudantes.

O artigo 12 da Resolução CNE/CP n. ${ }^{\circ} 1$ de 2002 foi responsável por definir o lugar da prática no currículo, articulando-a em diversos momentos do curso, deixando de restringi-la somente ao momento do estágio supervisionado (art. $12, \S 1^{\circ}$ Resolução $\mathrm{CNE} / \mathrm{CP}$ n. ${ }^{\circ} 1$ de 2002), ao garanti-la em todo o processo formativo (art. 12, § $2^{\circ}$ Resolução CNE/CP n. ${ }^{\circ} 1$ de 2002) contemplando os componentes curriculares e não apenas as disciplinas pedagógicas (art. 12, § $3^{\circ}$ Resolução CNE/CP n. 1 de 2002).

Já no artigo 13 da Resolução CNE/CP n. 1 de 2002 tem-se o embrião da diferenciação - mais nítida nas demais Resoluções - entre estágio supervisionado e atividades práticas, ao recomendar que a dimensão prática deveria transcender o estágio. Para atingir este objetivo, nos parágrafos do referido artigo encontramos os seguintes direcionamentos: prática desenvolvida a partir de processos de observação e reflexão e resolução de situações problema (art. 13, $\S 1^{\circ}$ Resolução $\mathrm{CNE} / \mathrm{CP}$ n. ${ }^{\circ} 1$ de 2002) e enriquecimento da formação pelas Novas Tecnologias e Informação e Comunicação NTICs, narrativas e estudos de caso (art. 13, § $2^{\circ}$ Resolução CNE/CP n. ${ }^{\circ} 1$ de 2002).

Além destes artigos, recomenda-se o aprimoramento de práticas investigativas, (art. 2, IV Resolução CNE/CP n. ${ }^{\circ} 1$ de 2002), com o intuito de propiciar o desenvolvimento de competência necessária à inovação da educação, bem como o "aperfeiçoamento da prática pedagógica" conforme frisa o artigo $6^{\circ}$, inciso V, da mesma Resolução.

Em 2006, o Conselho Nacional de Educação promulga a Resolução n.1 instituindo Diretrizes para o curso de graduação em Pedagogia. O principal papel desta normativa foi determinar o caráter específico de licenciatura do curso, anteriormente concebido, nas mais diversas matrizes formativas (ASSIS, 2007).

Ademais, esta Resolução deveria ser interpretada complementarmente à Resolução anterior, que fez menção à futura publicação de diretrizes específicas para cada curso, como é o caso, e deu direcionamentos gerais acerca da formação docente, cujos pormenores foram tratados em cada área. Este fato, justifica a necessidade de iniciar a análise, a partir de 2002, 
embora este ato normativo estivesse fora do recorte temporal determinado por Dourado (2015).

No caso da Pedagogia a expressão "prática" deixa de ser algo difuso e toma corpo diante de um longo rol de aptidões determinadas no artigo $5^{\circ}$ da Resolução CNE/CP n. ${ }^{\circ} 1$ de 2006, que vão desde princípios e valores até atividades específicas de docência e gestão. Também como indicativo da Resolução anterior, dita-se como deve se constituir o curso, organizado por três núcleos, quais sejam: de estudos básicos, de aprofundamento e diversificação de estudos e de estudos integradores (art. 6º , I, II e III Resolução CNE/CP n..$^{\circ} 1$ de 2006). Tratam-se de ações a serem realizadas objetivando garantir o perfil do egresso presente no artigo $5^{\circ}$ da mesma Resolução.

Também em consonância com o disposto no caput do artigo 12 da Resolução CNE/CP n. ${ }^{\circ} 1$ de 2002, o artigo $7^{\circ}$ da Resolução CNE/CP n. ${ }^{\circ} 1$ de 2006, determina a quantidade de horas mínimas do curso em 3.200 horas de efetivo trabalho acadêmico, sendo que destas, 300 horas seriam destinadas ao estágio supervisionado na Educação Infantil e nas séries iniciais do Ensino Fundamental (art. $7^{\circ}$, II da Resolução CNE/CP n. ${ }^{\circ} 1$ de 2006); 100 horas para atividades teórico-práticas configuradas em iniciação científica, monitoria e/ou extensão (art. $7^{\circ}$, II da Resolução CNE/CP n. ${ }^{\circ} 1$ de 2006); e 2.800 horas às atividades formativas como aquelas relacionadas à prática e prática investigativa, configuradas por assistências em salas de aula, seminários, pesquisas, consultas à biblioteca e afins, e visitas a centros educacionais e/ou culturais (art. $7^{\circ}$, II da Resolução CNE/CP n. ${ }^{\circ} 1$ de 2006). Neste desenho, a prática é compreendida como um currículo em si, deixando de se restringir a um mero componente curricular.

A partir da aprovação da Resolução CNE/CEB n. 2 de 2015, revoga-se a Resolução CNE/CP n.1/2002, sendo mantida a Resolução CNE/CP n. ${ }^{\circ} 1$ de 2006, apesar de sua proposta de redefinição do desenho formativo para todos os cursos de licenciatura em geral, no país. Entende-se que o seu nível de detalhamento é de alta complexidade, ao propor a forma três tipos de cursos de licenciatura: 1) base comum nacional para a formação dos profissionais do magistério para a educação básica (Capítulo II da Resolução CNE/CEB n. ${ }^{\circ} 2$ de 2015); 2) do egresso da formação inicial e da formação continuada (Capítulos III e VI da Resolução CNE/CEB n. 2 de 2015); 3) da formação inicial do magistério da Educação Básica em nível superior (Capítulos IV e V Resolução CNE/CEB n. ${ }^{\circ} 2$ de 2015).

A título de comparação, é no artigo 13 , parágrafo $1^{\circ}$ e incisos que a carga horária do curso é definida. As 3.200 horas mínimas são as mesmas da Resolução de 2006, mas a distribuição foi bastante alterada. O curso deve prever 400 horas de prática como componente curricular, que não deve ser confundida com as 400 horas de estágio supervisionado. Soma-se a isso, pelo menos 2.200 horas de atividades formativas estruturadas dentro dos três núcleos (similares aos previstos na resolução de 2006 e presentes no artigo 12 da Resolução CNE/CEB n. 2 de 2015) e 200 horas de atividades teórico-práticas. 
A novidade, perante a Resolução de 2006, é que as atividades formativas não estão mais diretamente vinculadas às atividades práticas, pois estas ganham quantidade de horas específicas destacando-se daquelas. Garcia (2016) ainda que faça estudo de distintas normativas, no que se refere a formação de professores, levanta a polêmica com relação às atividades práticas e estágio supervisionado, indicando que há uma intenção de articulação possível de ser identificada entre as normativas. Deste modo, o que se configura é um currículo fragmentado, que não ganha força com o aumento de horas fora de um núcleo de atividades formativas.

Neste sentido, apesar das particularidades destas Resoluções, e de se poder identificar certa evolução no nível de detalhamento dos temas tratados, nos levando, inclusive, a questionar o grau de autonomia deixado às Instituições de Educação Superior - IES, também são identificados alguns pontos em comum, particularmente no que se refere à relação entre a teoria e prática como componente curricular.

Na Resolução CNE/CP n. ${ }^{\circ} 1$ de 2002, o tema está contemplado no artigo $3^{\circ}$ de forma que a coerência entre formação e prática esperada fosse tomada como princípio norteador da formação para o exercício profissional específico. Neste contexto visava-se a simetria formativa, vale dizer, saber fazer aquilo que se espera que se faça (art. $3^{\circ}$, II, a Resolução $\mathrm{CNE} / \mathrm{CP}$ n. ${ }^{\circ} 1$ de 2002); aprendizagem como processo de construção de conhecimentos, habilidades e valores (art. $3^{\circ}$, II, b Resolução CNE/CP n. ${ }^{\circ} 1$ de 2002); competências desenvolvidas e suportadas por conteúdos (art. $3^{\circ}$, II, c Resolução CNE/CP n. ${ }^{\circ} 1$ de 2002); e avaliação como parte do processo de formação possibilitando diagnóstico (art. $3^{\circ}$, II, d Resolução CNE/CP n. ${ }^{\circ} 1$ de 2002). Nesta Resolução, o eixo articulador de teoria e prática foi também considerado um critério de organização das matrizes curriculares dos cursos de formação docente (art. 11, VI Resolução CNE/CP n. ${ }^{\circ} 1$ de 2002).

Já na Resolução CNE/CP n. ${ }^{\circ} 1$ de 2006, o inciso III do artigo $7^{\circ}$ deixa bastante claro que não haveria como desenvolver o conteúdo ou as atividades formativas em sala de aula, dissociado do que se nomeou "atividades práticas" nesta mesma Resolução e "práticas investigativas” da Resolução de 2002, conforme apresentado anteriormente.

Atualmente, com a Resolução CNE/CEB n. ${ }^{\circ} 2$ de 2015, inciso $\mathrm{V}$, parágrafo $5^{\circ}$ do artigo $3^{\circ}$, há um resgate da indissociabilidade entre teoria e prática enquanto princípio, em consonância com o preconizado na resolução de 2002; articulação que tem base nos conhecimentos científicos e didáticos e vínculo com o tripé universitário de ensino-pesquisaextensão (art. 207 CRFB/88).

Ainda que o artigo $3^{\circ}$ mencionado faça parte das considerações gerais, há previsão da práxis com expressão da articulação entre teoria e prática no capítulo da base comum, do qual faz parte o artigo $5^{\circ}$ (Resolução CNE/CEB n. ${ }^{\circ} 2$ de 2015). 
Este contexto deixa claro a tentativa das normas em evitar os dois modelos formativos distintos já destacados anteriormente por Saviani (2009); a atenção dada às questões práticas enquanto parte articuladora e definidora do currículo, vêm ao encontro da necessidade de se materializar a práxis - teoria praticante, prática teorizante.

\section{AS ADEQUAÇÕES CURRICULARES NO CURSO DE LICENCIATURA EM PEDAGOGIA (2002-2015): O CASO DA PRÁTICA COMO COMPONENTE CURRICULAR}

A proposta de se materializar a práxis como teoria praticante e prática teorizante presente nos dispositivos regulatórios dos cursos de licenciatura, entre os anos de 2002 e 2015, tem enfatizado a prática como componente curricular, com orientações específicas para o curso de licenciatura de Pedagogia.

Para Severino (1996), a questão da prática como componente curricular, em cursos de formação inicial e continuada de professores deve envolver elementos que envolvem a cultura (o saber teórico), a produção (habilitação técnica) e a política (sensibilidade ao caráter das relações sociais). Estes elementos apontados pelo autor, sem dúvida, podem ser identificados em Pareceres emitidos pelo Conselho Nacional de Educação, nos últimos anos, com o intuito de orientar os dispositivos legais com relação à prática como componente curricular.

QUADRO 2. Antecedente histórico-normativo da prática como componente curricular

\begin{tabular}{|c|c|}
\hline Parecer & Orientação \\
\hline $\begin{array}{ll}\text { Parecer } & \text { CNE/CP } \\
\text { n.9/2001 }\end{array}$ & $\begin{array}{l}\text { [...] instituir tempos e espaços curriculares diversificados como oficinas, } \\
\text { seminários, grupos de trabalho supervisionado, grupos de estudo, tutorias e } \\
\text { eventos, atividades de extensão, entre outros capazes de promover e, ao } \\
\text { mesmo tempo, exigir dos futuros professores atuações diferenciadas, } \\
\text { percursos de aprendizagens variados, diferentes modos de organização do } \\
\text { trabalho, possibilitando o exercício de diferentes competências a serem } \\
\text { desenvolvidas (p. } 25 \text {, grifo nosso) }\end{array}$ \\
\hline $\begin{array}{l}\text { Parecer CNE/CP n. } \\
\text { 28/2001 }\end{array}$ & $\begin{array}{l}\text { A prática como componente curricular é, pois, uma prática que produz } \\
\text { algo no âmbito do ensino. Sendo a prática um trabalho consciente (...) de } \\
\text { apoio do processo formativo, a fim de dar conta dos múltiplos modos de } \\
\text { ser da atividade acadêmico- científica. Assim, ela deve ser planejada quando } \\
\text { da elaboração do projeto pedagógico e seu acontecer deve se dar desde o início } \\
\text { da duração do processo formativo e se estender ao longo de todo o seu } \\
\text { processo. Em articulação intrínseca com o estágio supervisionado e com as } \\
\text { atividades de trabalho acadêmico, ela concorre conjuntamente para a } \\
\text { formação da identidade do professor como educador (p.31, grifo nosso). }\end{array}$ \\
\hline $\begin{array}{l}\text { Parecer CNE/CES n. } \\
15 / 2005\end{array}$ & $\begin{array}{l}\text { (...) a prática como componente curricular é o conjunto de atividades } \\
\text { formativas que proporcionam experiências de aplicação de conhecimentos } \\
\text { ou de desenvolvimento de procedimentos próprios ao exercício da } \\
\text { docência. Por meio destas atividades, são colocados em uso, no âmbito do } \\
\text { ensino, os conhecimentos, as competências e as habilidades adquiridos nas } \\
\text { diversas atividades formativas que compõem o currículo do curso. As } \\
\text { atividades caracterizadas como prática como componente curricular podem ser } \\
\text { desenvolvidas como núcleo ou como parte de disciplinas ou de outras } \\
\text { atividades formativas. Isto inclui as disciplinas de caráter prático } \\
\text { relacionadas à formação pedagógica, mas não aquelas relacionadas aos }\end{array}$ \\
\hline
\end{tabular}

\begin{tabular}{l|l|l|l|l|l|l} 
(C) Rev. Inter. Educ. Sup. & Campinas, SP & v.2 & n.2 & p.291-310 & maio/ago. 2016 & ISSN 2446-9424
\end{tabular} 


\begin{tabular}{|l|l|}
\hline Parecer CNE/CES n. & $\begin{array}{l}\text { fundamentos técnico-científicos correspondentes a uma determinada área } \\
\text { do conhecimento (p.32, grifo nosso). }\end{array}$ \\
\hline & $\begin{array}{l}\text { Os critérios de organização da matriz curricular, bem como a alocação de } \\
\text { tempos e espaços curriculares, se expressam em eixos em torno dos quais se } \\
\text { articulam dimensões a serem contempladas. Nas licenciaturas em educação } \\
\text { infantil e anos iniciais do ensino fundamental, cursos de pedagogia, a serem } \\
\text { desenvolvidos em projetos de cursos articulados, deverão preponderar os } \\
\text { tempos dedicados à constituição de conhecimento sobre os objetos de } \\
\text { ensino e, nas demais licenciaturas, o tempo dedicado às dimensões } \\
\text { pedagógicas não será inferior à quinta parte da carga horária total (p.32, } \\
\text { grifo nosso) }\end{array}$ \\
\hline
\end{tabular}

Fonte: Pareceres do CNE.

O quadro 2, ao destacar o antecedente histórico-normativo da prática como componente curricular, indica que este elemento formativo foi compreendido como:

a) Tempo e espaços diversificados, bem como à percurso de aprendizagem variada (2001);

b) Processo formativo fundamental à formação da identidade do egresso como educador (2005);

c) Momento constitutivo do conhecimento como objeto de ensino em um projeto pedagógico articulado (2015).

Neste sentido, a prática como componente curricular caracteriza-se, desde o ano de 2001, ora pela perspectiva da formação profissional e em outros momentos históricos pela perspectiva do desenvolvimento profissional (ANDRÉ, 2010; FIORENTINI; CRECCI, 2013). É esse dilema que o curso de licenciatura em Pedagogia tem enfrentado, ao destacar (Resolução CNE/CP n.1/2006), de acordo com o artigo $2^{\circ}$, parágrafo $1^{\circ}$ que:

Compreende-se a docência como ação educativa e processo pedagógico metódico e intencional, construído em relações sociais, étnico-raciais e produtivas, as quais influenciam conceitos, princípios e objetivos da Pedagogia, desenvolvendo-se na articulação entre conhecimentos científicos e culturais, valores éticos e estéticos inerentes a processos de aprendizagem, de socialização e de construção do conhecimento, no âmbito do diálogo entre diferentes visões de mundo (CONSELHO NACIONAL DE EDUCAÇÃO, 2006).

A fim de atender aos princípios acima apontados que embasam o curso de licenciatura em Pedagogia, as IES possuem autonomia, respeitada às orientações nacionais em vigência, a realizarem adequações específicas, com o propósito de caracterizar o perfil do egresso, mediante as disposições oficias. 


\section{O CURSO DE LICENCIATURA EM PEDAGOGIA-UNICAMP: UMA ANÁLISE DAS ADEQUAÇÕES NORMATIVAS E CURRICULARES}

O Curso de Licenciatura em Pedagogia da Universidade Estadual de Campinas (UNICAMP) foi criado no ano de 1974, sendo reconhecido somente no ano de 1977. Inicialmente, sua finalidade era formar especialistas na área da educação, em especial três habilitações: Orientação Educacional, Administração Escolar e Supervisão Escolar, sem que se fizesse menção à formação para o magistério, fato que só foi alterado, a partir do ano de 1976 (FACULDADE DE EDUCAÇÃO - UNICAMP, 2016).

Até o ano de 1997, o curso de Licenciatura em Pedagogia-UNICAMP estruturava-se em um núcleo comum para todas as habilitações e um núcleo específico para cada habilitação escolhida (mínimo uma e no máximo duas habilitações).

O curso passou por várias reformas, em que se destacaram: a relação teoria-prática e as habilitações propostas (reformulação de 1079); ampliação e diversificação da didática na formação do pedagogo, bem como a ampliação da carga horária de estágios (reformulação de 1984); a obrigatoriedade da formação para o magistério nas séries iniciais, a pesquisa como eixo de formação, a criação do curso noturno (reformulação de 1992); a docência como base da formação, a formação teórica sólida e interdisciplinar, não fragmentada em habilitações, o eixo da pesquisa, a criação dos núcleos temáticos, a organização curricular por módulos bimestrais; o compromisso ético e político com a escola pública (reformulação de 1997) (FACULDADE DE EDUCAÇÃO - UNICAMP, 2016, p. 18).

Embora o antecedente histórico do curso de licenciatura em PedagogiaUNICAMP, aponte a opção por diferentes reformas, a fim de atender as demandas normativas e pedagógicas, a publicação das Diretrizes Curriculares para o Curso de Pedagogia, em maio de 2006, demandou a revisão de alguns aspectos curriculares, com destaque para os estágios supervisionados, as distintas práticas de formação e a carga horária do curso. Este fato contribuiu para que alguns aspectos específicos passassem a caracterizar o curso, entre os quais (FACULDADE DE EDUCAÇÃO, 2016):

- A docência torna-se base para a formação do pedagogo;

- A proposta de uma formação integrada e multidisciplinar, superando a fragmentação existente com as habilitações específicas;

- A incorporação da gestão como componente central da formação;

- A ampliação da perspectiva de formação do pedagogo para além da visão disciplinar;

- Destaca a centralidade da pesquisa e do estágio curricular para o processo de formação;

- Ampliação de carga horária para a formação em Pedagogia. 
Essas alterações foram incorporadas, a partir de uma reforma curricular constituída em diversas instâncias da Faculdade de Educação - UNICAMP -, e implementadas, no ano de 1998. Apesar do caráter inovador da proposta, a questão do eixo da pesquisa, os estágios curriculares, os núcleos temáticos, a grade curricular disciplinar continuaram sendo discutidos e aperfeiçoados, até o ano de 2006, em momentos de avaliação semestral assembleias e avaliações individuais dos estudantes -, bem como junto à Comissão de Pedagogia e seis Departamentos ${ }^{4}$ da unidade.

Fato que foi incorporado ao debate institucional, em Seminários do Curso de Pedagogia e Estágio Curricular Supervisionado, promovidos pela Coordenação do Curso, ao considerar os desafios existentes para adequar o projeto pedagógico em vigência às novas demandas de formação propostas, mediante a tramitação nacional de tratativas presentes no Parecer CNE/CES n. 15/2005, e, posteriormente na Resolução CNE/CP n. ${ }^{o} 1$ de 2006.

Assim, após as discussões realizadas durante os Seminários de Pedagogia e Seminários de Estágio Curricular Supervisionado, no decorrer do ano de 2006, o currículo passou a ser analisado pelos princípios anteriormente delineados e assumidos, mas também pela incorporação dos seguintes aspectos:

- Eixo da pesquisa vinculada à prática desde o primeiro semestre do curso;

- Adoção de uma perspectiva multidisciplinar e de trabalho coletivo no processo formativo;

- Valorização de experiências não disciplinares de formação;

- Reformulação dos núcleos temáticos, mantendo-se o princípio da interdisciplinaridade;

- Reorganização da nomenclatura, ementas e período de oferta das disciplinas.

- Delimitação do lócus e forma de registro do estágio curricular supervisionado:

a) Estágios que contemplem o ensino, bem como a vivência na escola em sua totalidade, em que se inclui a gestão democrática, o projeto político pedagógico e outras dimensões do cotidiano escolar;

b) Estágio que contemple a educação infantil, as séries iniciais do ensino fundamental, a educação de jovens e adultos, além dos espaços e experiências de educação não-escolar e não-formal;

\footnotetext{
${ }^{4}$ A Faculdade de Educação da Unicamp, criada em 1972, é constituída por seis Departamentos: Departamento de Política, Administração e Sistemas Educacionais (DEPASE), Departamento de Psicologia Educacional (DEPE), Departamento de Ciências Sociais na Educação (DECISE), Departamento de Filosofia e História da Educação (DEFHE), Departamento de Ensino e Práticas Culturais (DEPRAC), Departamento de Educação, Conhecimento, Linguagem e Arte (DELART)
} 
c) A necessidade de elaboração de um projeto de estágio que possibilite o estabelecimento de convênios com as redes públicas e que não seja dependente de iniciativas individuais, quer seja do professor, quer seja do aluno. Nesta perspectiva, é importante que as escolas conveniadas participem da construção de uma proposta de estágio, e que se estabeleça uma relação de reciprocidade entre as mesmas e a Faculdade de Educação;

d) A formulação de uma proposta de estágio curricular supervisionado que contemplasse a Faculdade de Educação coletivamente.

e) Realização do estágio curricular supervisionado, a partir do $5^{\circ}$ semestre do curso, a fim de permitir a imersão do aluno nos contextos mencionados.

O novo currículo do curso de licenciatura em Pedagogia-UNICAMP, após as adequações apontadas, foi implementado em 2008, sendo reconhecido após renovação de seu credenciamento pela Portaria CEE-SP n. 289 de 01/07/2011 ${ }^{5}$. Assim, a estrutura do curso passa a se constituir do seguinte modo:

QUADRO 3. Estrutura Curso de Pedagogia-UNICAMP após adequação curricular 2008.

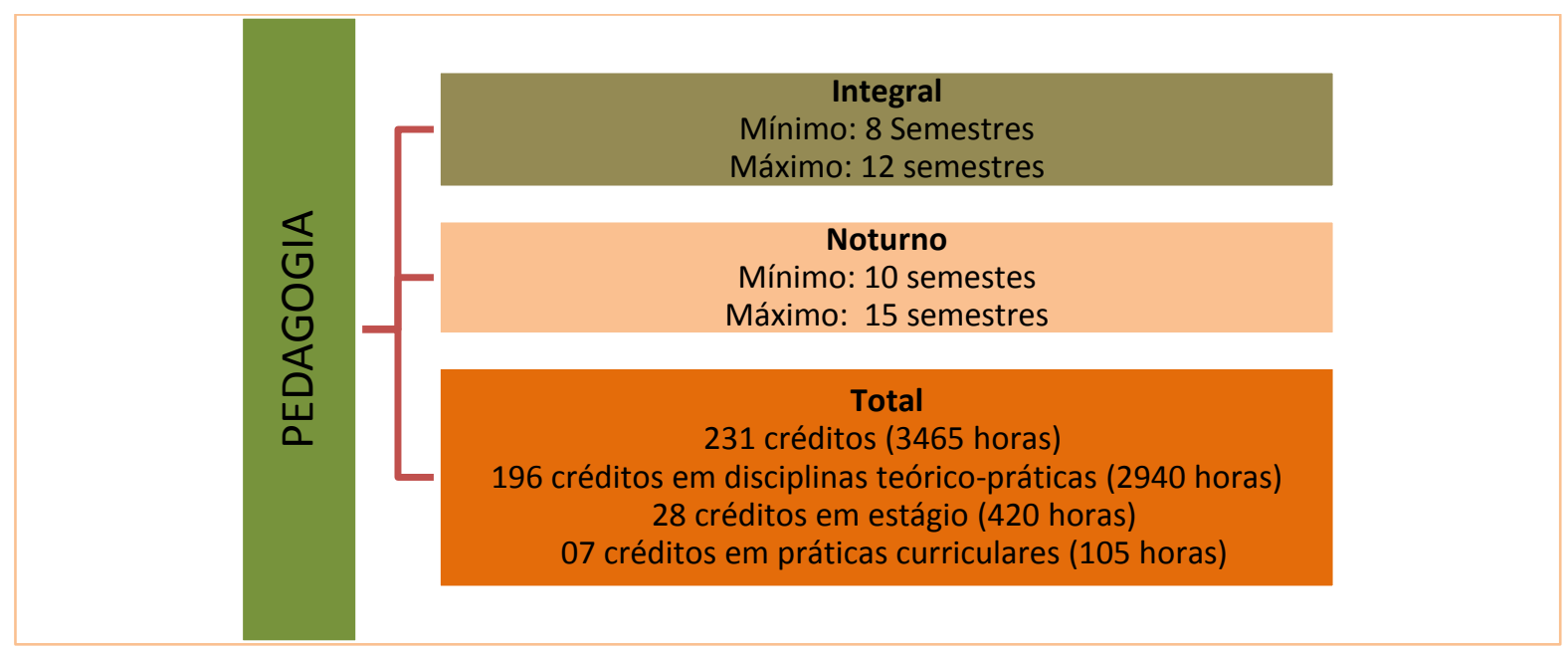

Fonte: Projeto Pedagógico do Curso de Pedagogia - Faculdade de Educação/UNICAMP (2016)

E em meio às novas proposições estabelecidas para o referido curso, a Faculdade de Educação- UNICAMP - aprova na Congregação em dezembro de 2008, o Documento intitulado: "Para uma política de estágios da FE" (2008), definindo, portanto, os princípios para os estágios curriculares supervisionados para os cursos de licenciatura e licenciatura em Pedagogia.

\footnotetext{
${ }^{5}$ O Curso de Licenciatura em Pedagogia da Faculdade de Educação da Universidade Estadual de Campinas (UNICAMP), ao pertencer ao conjunto de universidades mantidas pelo Governo do Estado de São Paulo, depende de normatização, autorização e avaliação direta do Conselho Estadual de Educação de São Paulo (CEESP), que o faz a cada cinco anos em cursos oferecidos pela Unicamp, USP (Universidade de São Paulo) e Unesp (Universidade Paulista).
} 
Nos anos de 2011 e 2012 foram realizados Fóruns de Avaliação do Curso de Pedagogia, com a participação de docentes e estudantes, com o objetivo de avaliar o funcionamento do currículo em vigência. De modo a subsidiar o diagnóstico, inicialmente organizou-se um grupo focal envolvendo docentes e chefes de departamentos, de modo a identificar os aspectos positivos, bem como as áreas com necessidade de adequação. Posteriormente, Grupos de Trabalho (GT's) foram estabelecidos em quatro áreas fundamentais: estágio curricular supervisionado, disciplinas, trabalho de conclusão de curso e gestão do currículo.

O período de realização dos Fóruns de Avaliação do Curso de Pedagogia se justificou pelo fato de corresponder aos anos de conclusão da primeira turma do período integral (2011) e noturno (2012) adequadas ao novo currículo proposto, desde o ano de 2008. Após a realização dessas avaliações, das discussões feitas em Assembleias semestrais de Avaliação de Curso, reuniões da Comissão de Pedagogia e aplicação de questionários discentes de avaliação de disciplinas, evidenciou-se a necessidade de adequações curriculares, que passam a integrar o currículo, a partir do ano de 2015:

- Junção de disciplinas: o caso das disciplinas Pesquisa e Prática Pedagógica e Seminário de Integração Curricular: ambas deixam de ser oferecidas por três semestres, para apenas um semestre cada uma;

- Ampliação de créditos para a disciplina Avaliação Educacional, compreendendo a relevância da temática para a formação de pedagogos.

Em meio ao processo de adequação curricular do curso de licenciatura em PedagogiaUNICAMP, após a realização de diagnóstico e avaliação, o Conselho Estadual de Educação de São Paulo (CEE-SP) no ano de 2012, fixa as Diretrizes Curriculares Complementares para a Formação de Docentes para a Educação Básica nos Cursos de Graduação de Pedagogia, Normal Superior e Licenciaturas, oferecidos pelos estabelecimentos de ensino superior vinculados ao sistema estadual, através da Deliberação CEE-SP n ${ }^{0} 111 / 2012$, e posteriormente, pela Deliberação CEE-SP $n^{0} 126 / 2014$, que altera o texto da normativa anterior.

Assim, diante desta nova demanda era preciso readequar o curso de licenciatura em Pedagogia, para além de suas demandas específicas, mas também em atendimento às proposições normativas, que orientavam uma nova redistribuição da carga horária ${ }^{6}$ :

\footnotetext{
${ }^{6}$ Deliberação CEE-SP n ${ }^{0}$ 111/2012 e Deliberação CEE-SP n ${ }^{\circ}$ 126/2014.
} 
I - 800 (oitocentas) horas para formação científico-cultural; II - 1.600 (mil e seiscentas) horas para formação didático-pedagógica específica para a pré-escola e anos iniciais do ensino fundamental; III - 400 (quatrocentas) horas para estágio supervisionado; IV - 400 (quatrocentas) horas do Curso de Pedagogia para a formação de docentes para as demais funções previstas na Resolução CNE/CP n. $01 / 2006$.

Portanto, além da adequação curricular com o propósito de atender às indicações do diagnóstico e avaliação do curso de licenciatura em Pedagogia, realizados pela comunidade da Faculdade de Educação - UNICAMP - o projeto pedagógico de 2015 também realiza adequações às normativas do CEE-SP, com destaque: alteração de ementas de disciplinas, aumento da oferta de disciplinas com carga horária, voltadas à prática pedagógica, criação de disciplinas como Educação de Jovens e Adultos e Estudo e Produção Acadêmica ${ }^{7}$.

\section{O ESTÁGIO CURRICULAR SUPERVISIONADO E A PRÁTICA COMO COMPONENTE CURRICULAR NO CURSO DE LICENCIATURA EM PEDAGOGIA DA UNICAMP}

Ainda que o curso de Pedagogia-UNICAMP ofereça disciplinas específicas de estágio curricular supervisionado, em que se articulam discussões em sala de aula e atividades de campo, em situação especial estão às disciplinas EP 377 - Planejamento Educacional e Estágio Supervisionado em Gestão Escolar e EP 376 - Prática de Ensino e Estágio Supervisionado nos Anos iniciais do Ensino Fundamental. Com vistas a marcar encontro entre as discussões em sala de aula e o cotidiano escolar, estabeleceu-se as referidas disciplinas como introdutórias ao estágio curricular supervisionado, que via de regra, possui caráter majoritário de orientação. Nelas, há um trabalho de discussão diretamente vinculada aos conteúdos de Planejamento Educacional (também discutidos na perspectiva teóricoprática pela disciplina EP 164 - Organização do Trabalho Pedagógico e Gestão Escolar) e de Prática de Ensino (também discutidos na perspectiva teórico-prática pelas disciplinas específicas dos anos iniciais do Ensino Fundamental) com a rotina da escola.

Não há, nesta proposta, uma sobreposição de conhecimentos, mas uma convergência, que até o presente momento, tem se mostrado prática interessante na composição curricular do curso. Na Faculdade de Educação- UNICAMP, o estágio curricular supervisionado ocorre a partir do $5^{\circ}$ semestre do curso, visando proporcionar ao aluno imersão / vivência em distintos campos de estágio, na dimensão da docência e da gestão democrática, tanto em espaços formais quanto não-formais. A data de início do estágio curricular supervisionado não segue, obrigatoriamente, o calendário acadêmico da UNICAMP, mas sim o calendário das escolas, como é o caso do período de planejamento, que antecede ao período letivo e vem ao encontro da proposta dos estágios curriculares supervisionados relacionados à gestão.

\footnotetext{
${ }^{7}$ Desde outubro de 2015, o projeto pedagógico do curso de licenciatura em Pedagogia da Unicamp encontra-se em avaliação, junto ao Conselho Estadual de Educação de São Paulo (CEE-SP). Aguarda parecer final no que se refere à adequação curricular e normativa realizada no ano de 2015.
} 
De acordo com Projeto Político do Curso de Pedagogia-UNICAMP (2016), os estágios curriculares supervisionados têm como princípios:

- A promoção do diálogo entre as várias áreas do conhecimento e entre os diferentes níveis de Educação Básica;

- A construção de projetos, considerando a aproximação entre os docentes e departamentos da Faculdade de Educação e diferentes áreas de conhecimento;

- A compreensão do estágio a partir de uma perspectiva que permita constante diálogo, construção, elaboração e ressignificação dos elementos teórico-práticos;

- A compreensão da escola como campo de estágio imprescindível, visando inclusive, à ampliação do olhar deste futuro profissional para a instituição escolar e o trabalho docente que compreende tanto aquele voltado às atividades com os estudantes em sala de aula, quanto àquelas relacionadas à gestão do processo educacional;

- O incentivo à diversificação dos campos quanto à localização geográfica, situação sócio-econômica-cultural da comunidade, práticas educativas desenvolvidas, ampliação das atividades, entre outros. Defendendo-se que o estágio ocorra, preferencialmente, através de convênios firmados com instituições públicas;

- A vivência dos estudantes em distintos campos de estágios na área da educação, entre os quais podemos destacar os estágios disciplinares e não disciplinares na escola, e estágios relativos aos outros espaços educativos.

Ao definir os princípios que orientam o estágio curricular supervisionado, entende-se que esse momento torna-se convergente às discussões teórico-práticas estabelecidas, ao longo do curso, conferindo significado aos conhecimentos científico-culturais e didáticopedagógicos, consolidando a formação inicial do docente da educação infantil e dos anos iniciais do ensino fundamental, bem como da gestão educacional.

Desse modo, além do estágio curricular supervisionado, a prática curricular definida como atividade de formação extracurricular, com carga didática de 105 horas, a ser realizada, ao longo do curso, é compreendida como um dos eixos integradores do curso de PedagogiaUNICAMP. Entre as atividades consideradas como prática curricular destacam-se: participação em congressos, seminários, simpósios, colóquios, mesas redondas; audiência de defesas de dissertação ou tese; trabalhos de iniciação científica; monitorias; estágios extracurriculares; intercâmbios, participação em grupos de pesquisa da Faculdade de Educação/UNICAMP; apresentação de trabalhos em eventos científicos; representação estudantil; participação em atividades culturais no âmbito da Faculdade de Educação e da $U N I C A M P^{8}$.

\footnotetext{
${ }^{8}$ Ver Projeto Político Pedagógico do Curso de Pedagogia - Unicamp (2016).
}

\begin{tabular}{l|l|l|l|l|l|l} 
(c) Rev. Inter. Educ. Sup. & Campinas, SP & v.2 & n.2 & p.291-310 & maio/ago. 2016 & ISSN 2446-9424 \\
\hline
\end{tabular}


QUADRO 4. Validação de crédito e carga horária do Curso de Pedagogia-UNICAMP ${ }^{9}$
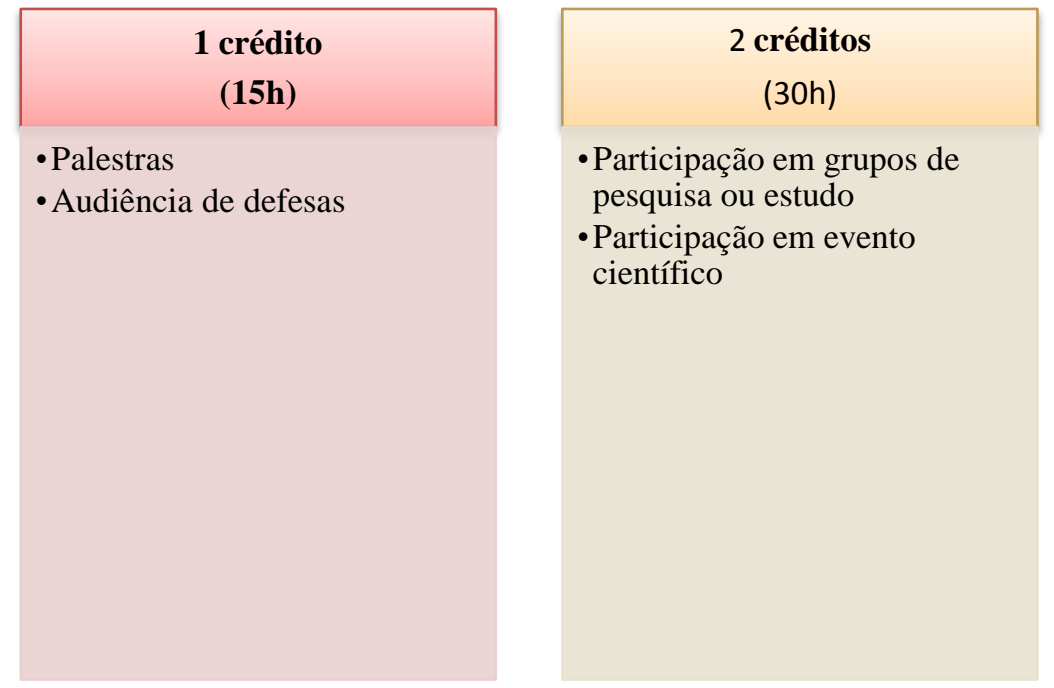

\begin{tabular}{l}
\multicolumn{1}{c|}{$\mathbf{3}$ créditos } \\
\multicolumn{1}{|c|}{$\mathbf{4 5 h})$} \\
\hline - Estágio extracurricular \\
- Atuação na área da Educação \\
- Iniciação Científica \\
- Monitoria Programa de Apoio \\
Didático \\
- Intercâmbio \\
- Representação Estudantil \\
- Apresentação de trabalho em \\
eventos \\
- Publicação de trabalho \\
científico \\
- Artigos científicos \\
- Cursos na área de Educação
\end{tabular}

Fonte: Projeto Político Pedagógico do Curso de Pedagogia - UNICAMP (2016).

Os critérios ${ }^{10}$ utilizados para a análise das atividades são dispostos considerando que:

- As atividades sejam realizadas durante todo o curso de Pedagogia;

- O estudante deverá realizar, no mínimo, três tipos diferentes de atividades, proporcionando a diversificação destas;

- A validação dos créditos deverá ser comprovada mediante a apresentação de certificados, declarações originais ou cópias acompanhadas dos originais;

- Serão validadas apenas as atividades com data após o ano de ingresso do estudante no curso.

Neste sentido, o estágio curricular supervisionado e a prática curricular constituem um núcleo de formação que têm o intuito de estabelecer uma relação teórico-pratica com ênfase no magistério da educação infantil, anos iniciais do ensino fundamental, bem como para a gestão educacional, ao longo de todo curso, de forma integrada aos demais (Quadro 5).

\footnotetext{
${ }^{9}$ Idem.

${ }^{10}$ Idem.
} 
QUADRO 5. Integração dos núcleos de formação do curso de Pedagogia-UNICAMP

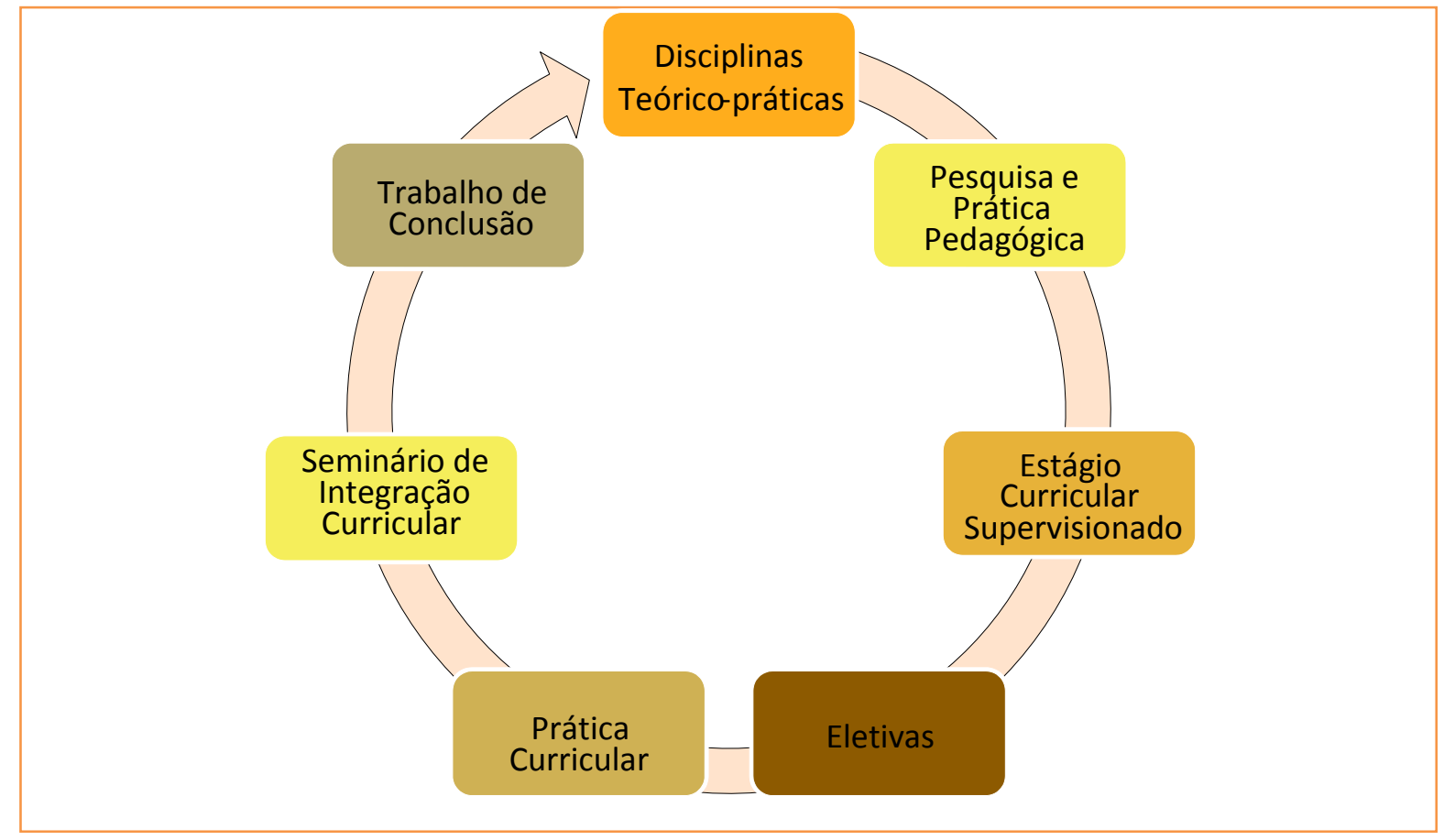

Fonte: Projeto Pedagógico do Curso de Pedagogia-UNICAMP (2016)

Como se observa no quadro 5, o desenho do curso de Pedagogia-UNICAMP estrutura-se na integração entre os núcleos de formação (disciplinas teórico-prática, estágio curricular supervisionado, disciplinas eletivas, prática curricular, integração curricular e trabalho de conclusão de curso). Esse processo de integração do modo em que se configura, atende diretamente às adequações normativas e curriculares em âmbito nacional e estadual.

Contudo, esta proposta apresenta alguns desafios que continuam a fomentar a adequação deste projeto, a partir da dinâmica institucional da Faculdade de Educação, com destaque às diferentes possibilidades de articulação entre os núcleos de formação e a consolidação de um projeto interdisciplinar, fato que ainda não se consolidou.

\section{CONSIDERAÇÕES FINAIS}

No que tange a uma análise das adequações normativas e curriculares do curso de Pedagogia, entre os anos de 2002 e 2015, no Brasil, alguns aspectos chamam a atenção:

1. Diversas orientações foram constituídas e aprovadas, nesse período, dificultando a constituição de um projeto nacional de formação de professores, pois em um momento a prática como componente curricular ganha destaque, em outros há preponderância dos conteúdos que embasam as disciplinas ou os estágios curriculares supervisionados passam a ser valorizados em detrimento dos demais núcleos de formação; 
2. Não há qualquer tipo de integração entre às normativas gerais para a formação de professores e o atendimento às especificidades presentes no Curso de Licenciatura em Pedagogia, em âmbito nacional;

3. As orientações referentes à carga didática destinada aos Cursos de Licenciatura, em particular do Curso de Pedagogia precisam estabelecer relação direta com as diferentes proposições e concepções de formação de professores que historicamente têm influenciado o debate e, consequentemente sua estrutura;

4. A heterogeneidade dos espaços de formação pedagógica deve ser reconhecida, no que se refere à caraterização dos distintos lócus, em que o processo pode ocorrer.

Particularmente, o Curso de Licenciatura em Pedagogia-UNICAMP é um exemplo de como a dinâmica nacional e estadual influenciam seu desenho institucional, mesmo após o estabelecimento de uma proposta de reforma curricular que estava em vigência, desde o ano de 2008. Em meio ao processo de implementação da medida, as normativas nacionais e estadual tiveram que ser incorporadas à proposta em curso, interferindo em sua consolidação, mediante o desafio de realização das adequações às legislações vigentes e ao currículo proposto.

Entende-se, a partir desta análise que as normativas e o currículo a ser estabelecido ao Curso de Pedagogia, no Brasil necessitam de tempo para que o processo de implementação, consolidação e avaliação das medidas sejam levadas em consideração. Caso contrário, projetos pedagógicos constituídos por iniciativas institucionais podem ser sobrepostos às determinações legais e curriculares, desconsiderando, assim, as demandas locais e a relevância de sua integração a uma política de formação nacional.

\section{REFERÊNCIAS}

ANDRÉ, Marli. Formação de professores: a constituição de um campo de estudos. Educação, Porto Alegre, v. 33, n. 3, p. 174-181, set./dez. 2010. Disponível em: $<$ http://revistaseletronicas.pucrs.br/ojs/index.php/faced/article/viewFile/8075/5719> Acesso em 04/05/2016.

ASSIS, Ana Elisa Spaolonzi Queiroz. Especialistas, professores e pedagogos: afinal, que profissional é formado na pedagogia? Dissertação de Mestrado. PUC-Campinas. 226 p. 2007. Disponível em: http://livros01.livrosgratis.com.br/cp041274.pdf Acesso em: 07 Ago. 2016.

BRASIL. Constituição de República Federativa do Brasil de 1988. Disponível em: http://www.planalto.gov.br/ccivil_03/constituicao/constituicaocompilado.htm. Acesso em: 07 Ago. 2016.

BRASIL. Lei n. ${ }^{0} 11.788$ de 2008. Dispõe sobre o Estágio de Estudantes (...). Disponível em: http://www.planalto.gov.br/ccivil_03/_ato2007-2010/2008/lei/111788.htm. Acesso em: 07 Ago. 2016. 
CONSELHO NACIONAL DE EDUCAÇÃO. Resolução CNE/CP n. 1 de 2002. Disponível em: http://portal.mec.gov.br/cne/arquivos/pdf/rcp01_02.pdf. Acesso em: 07 Ago. 2016.

CONSELHO NACIONAL DE EDUCAÇÃO. Resolução CNE/CP n. 1 de 2006. Disponível em: http://portal.mec.gov.br/cne/arquivos/pdf/rcp01_06.pdf. Acesso em: 07 Ago. 2016.

CONSELHO NACIONAL DE EDUCAÇÃO. Resolução CNE/CEB n. 2 de 2015. Disponível em: http://pronacampo.mec.gov.br/images/pdf/res_cne_cp_02_03072015.pdf Acesso em: 07 Ago. 2016.

DOURADO, Luiz Fernandes. Diretrizes curriculares nacionais para a formação inicial e continuada dos profissionais do magistério da educação básica: concepções e desafios. In: Educ. Soc., Campinas, v. 36, n. 131, p. 299-324, Junho 2015. Disponível em: $<$ http://www.scielo.br/scielo.php?script=sci_arttext\&pid=S010173302015000200299\&lng=en\&nrm=iso>. Acesso em: 07 Ago. 2016.

\section{FACUlDADE DE EDUCAÇÃO. UNICAMP. Projeto Político Pedagógico do Curso de} Licenciatura em Pedagogia. Campinas, 2016 (mimeo).

FIORENTINI, Dario; CRECCI, Vanessa. Desenvolvimento Profissional DOCENTE: Um Termo Guarda-Chuva ou um novo sentido à formação? Form. Doc., Belo Horizonte, v. 05, n. 08, p. 11-23, jan./jun. 2013. Disponível em:

<file:///C:/Users/User/Downloads/Desenvolvimento\%20Profissional\%20Docente\%20Um\%20Termo\%20GuardaChuva\%20ou\%20um\%20novo\%20sentido\%20\%C3\%A0\%20 forma\%C3\%A7\%C3\%A3o-.pdf> Acesso em 04/05/2016.

GARCIA, Maria Manuela Alves. Políticas curriculares e profissionalização: saberes da prática na formação inicial de professores. In: Educ. rev., Belo Horizonte , v. 32, n. 2, p. 131-158, Junho 2016. Disponível em: $<$ http://www.scielo.br/scielo.php?script=sci_arttext\&pid=S010246982016000200131\&lng=en\&nrm=iso>. Acesso em: 07 Ago. 2016.

GATTI, Bernardete Angelina. A formação inicial de professores para a educação básica: as licenciaturas. Revista USP. São Paulo, n. 100, p. 33-46, dez.jan.fev. 2013/2014a. Disponível em: <file:///C:/Users/User/Downloads/76164-103937-1-SM\%20(2).pdf> Acesso em 04/05/2016.

GATTI, Bernardete Angelina. Formação inicial de professores para a educação básica: pesquisas e políticas educacionais. Est. Aval. Educ., São Paulo, v. 25, n. 57, p. 24-54, jan./abr. 2014b.

\section{INSTITUTO NACIONAL DE ESTUDOS E PESQUISAS EDUCACIONAIS ANÍSIO} TEIXEIRA. Censo da Educação Superior. Relatório técnico. INEP: Brasília, 2015. Disponível em: <http://download.inep.gov.br/download/superior/censo/2013/resumo_ tecnico_censo_educacao_superior_2013.pdf > Acesso em 18/08/2016.

LIBÂNEO, José C. Reflexividade e formação de professores: outra oscilação do pensamento pedagógico? In: Pimenta, Selma G. Ghedin, Evandro. (Org.). Professor reflexivo no Brasil: gênese e crítica de um conceito. 1ed.São Paulo: Cortez Editora, 2002, v, p. 7-224. 
SAVIANI, Demerval. Formação de professores: aspectos históricos e teóricos do problema no contexto brasileiro. Revista Brasileira de Educação v. 14. n. 40, p.143-155, jan./abr. 2009. Disponível em: <http://www.scielo.br/pdf/rbedu/v14n40/v14n40a12.pdf > Acesso em 04/05/2016.

SEVERINO, Antônio Joaquim. Apresentação. Educ. Pesquisa, São Paulo, v. 32, n. 3, 1996. 